\author{
MACIEJ JANOWSKI, MARIA CHEŁKOWSKA-ZACHAREWICZ \\ University of Silesia, Poland \\ Institute of Psychology
}

\title{
WHAT DO WE ACTUALLY MEASURE AS MUSIC-INDUCED EMOTIONS?
}

\begin{abstract}
The paper presents the results of a systematic review of 61 empirical studies in which emotions in response to music were measured. The analysis of each study was focused on the measurement of emotion components and the conceptualization of emotion both in hypothesis and discussion. The review does not support the claim that music evokes the same emotional reactions as life events do, especially modal emotions. Notably, neither a high intensity of feelings, nor intentionality were confirmed in relation to musical experiences, the emergence of specific action tendencies, or specific physiological changes. Based on the obtained results, it is recommended to use the terms "affect" or "music emotions" with reference to emotions experienced in reaction to music and to abandon the term "emotions" as misleading.
\end{abstract}

Keywords: emotions; affect; music emotions; emotional reactions to music.

\section{INTRODUCTION}

In everyday language (Fehr \& Russell, 1984; Johnson-Laird \& Oatley, 1989; Shaver, Schwartz, Kirson, O'Connor, 1987) and in some psychological theories (for a short review, see e.g. Kowalska \& Wróbel, 2017), emotion is associated with some basic categories such as happiness, sadness, fear, anger, guilt, or disgust. This approach is sometimes questioned (Barrett, 2006; Izard, 2007); however, when speaking about emotions, one must consider that scholars usually

Corresponding author: MARIA CHEŁKOWSKA-ZACHAREWICZ-University of Silesia, Institute of Psychology, ul. Grażyńskiego 53, 40-126 Katowice, Poland; e-mail address: maria.chelkowskazacharewicz@us.edu.pl 
bring these modalities to mind. In our paper we investigate whether the term "emotion" is applicable to music-induced experiences. We analyze the conceptualization of emotion in music-induced emotion research, but above all we seek to determine if the methods used in such research and the data collected allow for confirming that the properties measured are distinctive of emotions.

Emotions are a heterogeneous group of feelings. Many scholars divide them into two main groups: primary and secondary (Damasio, 2005), basic and nonbasic (Ekman, 1992, 1999; Shaver, Morgan, \& Wu, 1996), basic emotions and emotion schemas (Izard, 2007, 2009), basic and complex (Johnson-Laird \& Oatley, 1988), or utilitarian and aesthetic (Scherer, 2005).

The first group of emotions (e.g., primary or basic) are described as a set of relatively short and mainly intensive reactions to an event, be it real or existing only in the mind (Frijda, 1988; Goldsmith, 1994; Keltner \& Gross, 1999; Watson \& Clark, 1994), encompassing a specific experience (modality), cognitive and physiological changes, and motivation to undertake specific action (Davidson, 1994; Ekman, 1994; Frijda, 1988, 1994) important from the perspective of survival in the physical or social environment (Izard, 2009; Keltner \& Gross, 1999; Keltner \& Haidt, 2001). It is also often accompanied by characteristic forms of expression (Ekman, 1993; Matsumoto, Keltner, Shiota, Frank, \& O'Sullivan, 2008; Watson \& Clark, 1994). Many authors (Ekman, 1994; Frijda, 1994; Keltner \& Gross, 1999; Russell, 2003) have emphasized that emotion is intentional, which means that there is a distinct object in the person's perception towards which this experience is oriented (as in "fear of..." or "angry with...").

It is more difficult to characterize the second group of feelings (e.g., complex, aesthetic). Combining various concepts, it can be stated that they are evoked by conscious and deliberate consideration of a situation or a person (Damasio, 2005) based on learned associations or links between feelings and perceptions, images, or thoughts (Izard, 2007); they do not concern fundamental life tasks (Ekman, 1999; Johnson-Laird \& Oatley, 1988), but they are helpful in dealing with challenges within a given culture (Izard, 2007). In fact, this list of properties does not seem to be exhaustive, and it is easier to formulate a negative definition: they are emotions, but not basic ones.

\section{AFFECTIVE REACTIONS IN MUSIC RESEARCH}

The review of music emotion studies performed by Eerola and Vuoskoski (2013) revealed that affective reactions to music are described by different emo- 
tion models. Of the studies in which music-induced emotions were measured (see Gabrielsson, 2001, for the differentiation between emotions felt or induced by music and emotions perceived in music or expressed by music), most (47\%) referred only to the dimensional models of emotions, while the discrete emotion model and the music-specific emotion model were used rarely $(17 \%$ and $11 \%$, respectively). The remaining studies (26\%) relied on miscellaneous models of emotions.

In dimensional models every emotional response is described on a few dimensions. If there are two dimensions, they directly or indirectly correspond to the dimensions of affect, defined by Russell (2003) as "a neurophysiological state that is consciously accessible as a simple, nonreflective feeling that is an integral blend of hedonic (pleasure-displeasure) and arousal (sleepy-activated) values" (p. 147). Affect is the basis of emotions and mood (Russell, 2003), however, it must be remembered that affect dimensions are insufficient for comprehensive emotion description, because emotion is constituted by more elements than arousal and valence (Russell, 2003; Yik, Russell, \& Steiger, 2011).

Discrete emotion models usually relate to basic emotions (see e.g., Barrett, 1998; Eerola \& Vuoskoski, 2011; Izard, 2007) and postulate that all emotions are derivatives (but not a blend) of a limited number of universal innate emotions.

In the music-specific emotions model, the set of affective reactions is extended due to the empirically confirmed assumption that basic emotions are not adequate to describe a variety of feelings evoked by music (Zentner, Grandjean, $\&$ Scherer, 2008). The most popular list of reactions was proposed by Zentner et al. (2008) who aggregated feelings into nine groups: wonder, transcendence, tenderness, nostalgia, peacefulness, power, joyful activation, tension, sadness. Music-specific emotions seem to be non-basic or complex emotions.

Scherer (2004) describes specific music-induced feelings as aesthetic emotions and gives examples of this category: being moved, wonder, admiration, bliss, ecstasy, fascination, harmony, rapture, solemnity. Aesthetic emotions only partially overlap with the list of music-specific emotions proposed by Zentner and colleagues (2008), but their description seems to be helpful in the depiction of a wide spectrum of affective reactions induced by music. Somatic or behavioral elements of music-induced feelings are reactive, not proactive, so they do not prepare the person for a specific activity. Utilitarian emotions are triggered mainly by transactional appraisal (essential consequences for wellbeing), while aesthetic emotions result to a greater extent from intrinsic appraisal (properties of the stimulus). Admittedly, Scherer (2004) states that aesthetic emotions are not intensive, but qualitative analyses revealed very high levels of some of the mu- 
sic-induced experiences, namely ecstasy (Bicknell, 2007; Gabrielsson \& Wik, 2003; Gabrielsson, 2011), love, and being moved (Bicknell, 2007).

\section{AIM OF THE STUDY}

Based on the published research on emotions in reaction to music, in our review we set out to verify (1) if the methods used in studies yield data confirming properties of emotional reactions distinctive of modal (discrete, basic) emotions, (2) which of the definitions - modal emotions, music emotions or affect - best fit the obtained data, and (3) whether the definitions of emotions referred to in the hypotheses and in the Discussion sections are compatible with the obtained data.

Although it has previously been indicated that emotional reactions to music are rather different from emotions (Scherer, 2004), we examine the methodological aspects of the reviewed studies more thoroughly. We want to determine what properties of emotional reactions are measured in music emotion research and how this is related to the conceptualization of emotions and emotional reactions. Therefore, in our review we are looking for further arguments in the debate on the nature of emotional response to music.

\section{METHOD}

Definitions. In the review, we refer to three types of emotional reactions: (1) modal emotion - an episode of interrelated, synchronized changes of all or most organismic subsystems (motivational, cognitive, expressive, neurophysiological, and subjective feeling) in response to the evaluation of an external or internal event as being of major significance for personal goals or needs (Scherer, 2004), usually oriented towards an object (Ekman, 1994; Frijda, 1994; Keltner \& Gross, 1999; Russell, 2003), encompassing specific rapid subjective modal feelings (modality) of fairly high intensity, specific action tendency, mimic changes and/or vocal expression, and neurophysiological changes (Scherer, 2004); the list of modal emotions comprises: pride, elation, joy, satisfaction, relief, hope, interest, surprise, sadness, fear, shame, guilt, envy, disgust, contempt, and anger (Sacharin et al., 2012; Scherer, Shuman, Fontaine, \& Soriano, 2013); (2) music emotion - a feeling that has a modality different from any modal emotion; tentatively, the ensemble of music emotions contains feelings such as wonder, transcendence, peacefulness, power, being moved, awe, inspired, melancho- 
lia, nostalgia, or tenderness (Coutinho \& Scherer, 2017; Zentner et al., 2008); (3) affect - a neurophysiological state accessible to the consciousness as a simple, short-lasting, not object-focused, nonreflective (automatic) feeling that is an integral blend of hedonic and arousal values; affect may be described as pleasure/unpleasantness and low/high energy (Russel, 2003); illustrated graphically, the two dimensions of affect divide the space of emotional reactions into four affective quadrants, to which individual feelings can be assigned: pleasant high energy (e.g., elated), low energy level felt as a pleasant state (e.g., calm), negative high energy (e.g., jittery), and low energy felt as a negative state (gloomy; see Russell, 2003).

Criteria for Paper Inclusion. To verify whether the empirical data in music emotion research support the conclusion that affective reactions to music can be described in terms of modal emotions, we performed a systematic review. We searched for publications presenting empirical studies that focused on emotions induced by music, where authors claimed that their interest was in emotions rather than in other types of affective reactions. Therefore, the publications included in the review had to be available in English, include a description of empirical research, concern felt emotion in reaction to music, as well as include the word music in combination with emotion, felt, or induced in the title, abstract, or keywords. Papers were excluded if they explicitly focused on explored mood or affect induced by music or on emotion perceived in music. The search for relevant papers in peer-reviewed journals was conducted in PsycINFO and PsychARTICLES from inception to June 2018.

A total of 393 records were initially identified through database searching: 121 found with the phrase "music AND emotion AND felt" and 272 found with the phrase "music AND emotion AND induced." After the screening process that included title and abstract reading, 61 publications met the above criteria and were therefore selected for further scrutiny.

Criteria for Paper Review. In the analyzed studies we sought tools used for emotion assessment or physiological reaction measurement. We were looking for information on what emotions in reaction to music were measured. If the tool contained an open-ended questions, we assumed that it could measure an unlimited number of modal emotions. In the case of self-assessment questionnaires with close-ended questions, we checked for the presence of modal emotion properties (behavioral tendency, reaction to personally important situation, intentionality, mimic changes), the number of emotions measured and their modalities (e.g., anger, fear; see: definition of modal emotion above), the presence of terms specific to musical emotions (e.g., nostalgia, tenderness; see: definition of music 
emotion above), the presence of terms specific to affect (i.e., indication of valence and arousal). If the terms joyful (or happy), sad (or sorrowful), representative of both modal emotions and music emotions, were measured, we assumed that they were examples of music emotions if other music emotions were also studied. In other cases we presumed that joyful or sad described modal emotions.

In the next step, we reviewed research results to see if basic or music emotions were directly analyzed or reduced, for example, by factor analysis and to verify the results of the investigations. Additionally, in the analyzed papers we searched for the conceptualization of emotion in the hypotheses or in the Background and Discussion sections.

\section{RESULTS}

The detailed analysis of the reviewed publications is presented in Table 1 (see Appendix). Of the 61 studies analyzed, 32 measured basic emotions modalities, 20 measured music emotions or aesthetic emotions, and 29 measured emotional dimensions characteristic of affect (the numbers do not add up to 61 because in some papers several emotional categories were studied).

\section{Emotions Measured: Modalities and Intensity}

Terms relevant to modal emotions were used in 32 studies (52\%). In four of them only happiness and sadness were measured. In three studies (Lundqvist, Carlsson, Hilmersson, \& Juslin, 2009; Vuoskoski \& Eerola, 2011; Vuoskoski, Thompson, Mcllwain, \& Eerola, 2012) musically induced affective reactions described as basic emotions were explored, but in each case their level was low. Kreutz, Ott, Teichmann, Osawa, and Vaitl (2008) induced anger and fear using music, although these responses were markedly weaker than happiness, sadness, and peace evoked by other sets of musical pieces.

Thompson, Geeves, and Olsen (2019) used a self-report scale measuring anger and fear along with a scale measuring affect and music emotions and an open-ended questionnaire assessing reactions to death metal music. The data confirmed the possible induction of anger and fear, especially in non-fans of metal music: 49 respondents (51\%) reported anger, 20 (21\%) reported fear, $13(13 \%)$ reported disgust; the mean levels of these emotions were moderate or low. It must be noted, however, that Thompson and colleagues (2019) used songs 
as emotion-inducing stimuli, and their lyrics might have influenced respondents' reactions. What is more, some subjects may have regarded the music excerpts as noise, as in the following response: "It sounds like messed up teenagers making throaty, irritating noises about how bad their lives are. It's annoying. My ears were attacked" (p. 227).

When terms belonging to three or four basic emotion categories were applied (six studies: Etzel, Johnsen, Dickerson, Tranel, \& Adolphs, 2006; Johnsen, Tranel, Lutgendorf, \& Adolphs, 2009; Naji, Firoozabadi, \& Azadfallah, 2014; Song, Dixon, Pearce, \& Halpern, 2016; Tabei, 2015; Wu \& Sun, 2018), only emotions that differ on pleasure and arousal levels were used, e.g. happy, sad, and fearful (Johnsen et al., 2009) or happy, sad, angry, and relaxed (Song et al., 2016). In consequence, it can be concluded that the obtained data concern both emotions and affect.

Similarly, in 22 studies that explored more than four modal emotions, in many cases (e.g., Daly et al., 2014, 2015; Dibben, 2004; Egermann et al., 2011) researchers analyzed these emotions as belonging to two or four groups corresponding to the dimensions of affect. In the analyses they did not take into account the qualitative differences between measured emotions (i.e., when two modalities had comparable strength on affect dimensions but related to different reactions, as in fear and anger).

In a few studies, modal emotions such as anger, fear, or disgust were reported as having low or medium intensity while listening to music (e.g., Juslin, Harmat, \& Eerola, 2014; Kopec, Hillier, \& Frye, 2014; Kreutz et al., 2008) or as occurring very rarely (Juslin, Liljeström, Västfjäll, Barradas, \& Silva, 2008; Zentner et al., 2008). Anger-irritation and anxiety-fear usually appeared in social settings (Juslin et al., 2008), when subjects listened to music in other people's presence.

Coutinho and Scherer (2017) obtained data which confirmed that musically induced experiences of tense, uneasy, and nervous were slightly different from those of agitated, aggressive, angry and irritated. It is not clear if this observation argues that music can awake modal emotions. The authors merged them into two groups: Fear and Anger, but they included neither fear nor anger in a new music-induced affect checklist, because tense, uneasy, agitated, and aggressive turned out to be more relevant.

Juslin, Barradas, and Eerola (2015) found no differences in the level of interest-expectancy and anger-irritation in reaction to various musical pieces. However, the level of anger-irritation differed from anxiety-nervousness in the study by Juslin and colleagues (2014). 
It is worth mentioning that 35 studies explicitly analyzed feelings on the dimensions of affect ( 22 did not use terms referring to any modality), and in 20 reports music emotions were investigated.

\section{Emotions Measured: Other Properties Characteristic of Modal Emotions}

Three studies explored behavioral tendencies among other features of emotions. Thompson and colleagues (2019) analyzed data from an open-ended questionnaire pertaining to heavy metal music. Fans of this genre reported an increased level of motivation to engage in a wide variety of actions, including physical, artistic, or domestic activities, meeting with friends, working, or learning. Non-fans were motivated to terminate the situation of music listening. In both groups, a few people mentioned a desire to engage in aggressive behavior. In general, respondents reported a desire to constrain listening to the disliked music or to go on listening to the preferred musical excerpts. They also reported willingness to engage in various forms of action, depending on the situational context, e.g. physical, artistic or domestic activities, meeting with friends, working, or learning.

In two studies (Labbé, Glowinski, \& Grandjean, 2016; Labbé \& Grandjean, 2014) some respondents reported willingness to dance or move.

In none of the reviewed studies was the intentionality of emotions or the significance of the emotion-inducing situation/stimulus explicitly investigated. One study involved a question about the practical consequences for goals or plans in life (Juslin et al., 2014), but these remained unrelated to emotional reactions to music.

Changes in mimic expression, especially the activity of the corrugator and zygomaticus, were measured in three studies; however, in two of them (Juslin et al., 2014, 2015) these changes were not analyzed as a manifestation of modal emotions. The study by Lundqvist and colleagues (2009) revealed differences in muscle activity, but these generally concerned feelings differing on pleasure or arousal dimensions.

In 26 studies neurophysiological changes were measured, mainly in EEG, skin conductance, heart rate, or respiration. In six studies researchers measured chills. In general data confirmed the occurrence of bodily changes while listening to music. However, if we consider only those studies in which more than four modal emotions were analyzed, then results become inconclusive. Juslin et al. (2015) controlled skin conductance, chills, as well as zygomaticus and corrugator 
activity, but they analyzed them in the context of mechanisms arousing emotions (contagion, expectancy, memory, etc.) rather than emotional reactions per se. The situation was similar in the study by Juslin et al. (2014), who measured skin conductance, pulse rate, chills (in self-report), as well as zygomaticus and corrugator activity.

Some correlations between emotions and physiological reactions were found by Krumhansl (1997), who measured cardiac, vascular, electrodermal, and respiratory changes. For instance, anger co-occurred with higher skin conductance while fear correlated with respiration asynchrony, but Krumhansl mentioned that there was no congruence between results based on averaged data and those based on dynamic measurement.

Interesting outcomes were obtained by Vásquez-Rosati (2017). In her research, based on micro-phenomenological interviews, subjects described their reactions to music, for instance, as corporal sensations such as "lived body," "stiff body," or "pressure on body." Nevertheless, her analyses did not reveal any patterns of physical components in modal emotional reactions to music.

Chills, as a physiological reaction, were investigated in six studies. Two of these (Juslin et al., 2014, 2015), were focused on psychological mechanisms underlying emotional response to music and did not describe emotions. Baltes found convergence between chills and sadness, tension (Balteş \& Miu, 2014), wonder, and transcendence (Balteş, Avram, Miclea, \& Miu, 2011). Egermann and colleagues (2011) as well as Salimpoor, Benovoy, Longo, Cooperstock and Zatorre (2009) studied chills only in the context of emotions reduced to the dimensions of affect.

\section{Conceptualizations of Emotions}

In the majority of studies the conceptualization in the hypotheses referred to emotions, emotional reactions, or emotional experiences (32 studies, e.g. Kreutz et al., 2008; Song et al. 2016; Thompson et al., 2019). Out of these studies, investigating different emotion components, 11 involved neurophysiological measurement (e.g., Dibben, 2004; Gomez \& Danuser, 2007; Krumhans1, 1997), two measured mimic expression (Lundqvist et al., 2009; Juslin et al., 2014), and 15 measured more than four emotion modalities (e.g., Juslin et al., 2008; Kreutz et al., 2008; Vuoskoski et al., 2012), although in five of them the modalities were analyzed in terms of affect dimensions (Daly et al., 2014; Dibben, 2004; Egermann et al., 2011; Vernooi, Orcalli, Fabbro, \& Crescentini., 2016). Subjective feeling was the sole component of emotion measured in 21 of these studies 
(e.g., Jaquet, Danuser, \& Gomez, 2014; Larsen \& Stastny, 2011; Song et al., 2016). In eight studies the subjective feeling measurement concerned aesthetic emotions (e.g., Kawakami, Furukawa, Katahira, \& Okanoya, 2013; Krahé, Hahn, \& Whitney, 2015), 15 studies included emotional measurement of valence (e.g., Egermann \& McAdams, 2013; Kopec et al., 2014; Thompson et al., 2019), 13 studies involved the measurement of arousal (e.g., Egermann, Nagel, Altenmüller, \& Kopiez, 2009; Schubert, 2007; Vuoskoski et al., 2012), and in five studies the dimension measured was tension or dominance (e.g. Schubert, 2007, 2010; Thompson et al., 2019). In the studies where hypotheses referred to emotions, no motivational or cognitive component indicators were measured.

A similar number of studies referred to emotion in the discussion section (35, e.g. Johnsen et al., 2009; Juslin et al., 2008), while only two-third of these (24) referred to emotion conceptualization in the hypotheses (e.g., Krumhansl, 1997; Larsen \& Stastny, 2011; Lundqvist et al., 2009). Of the remaining 11 studies, three referred explicitly to dimensional models of emotions (Cheng, Wu, \& Yen, 2009; Evans \& Schubert, 2008; Salimpoor et al., 2009), four referred to music-induced emotions (e.g. Eerola, Vuoskoski, \& Kautiainen 2016; Trost, Frühholz, Cochrane, Cojan, \& Vuilleumier, 2015), two described the measured reactions as feelings (Coutinho \& Scherer, 2017; Juslin et al., 2015), and two others described them as positive or negative emotion (Balteş \& Miu, 2014; Labbé et al., 2016).

The conceptualization of music emotions or music-induced emotions in the hypotheses section appeared in 11 studies (e.g., Daly et al., 2015; Eerola et al., 2016; Labbé \& Grandjean, 2014), and eight of them, apart from subjective feeling measurement, included a neurophysiological measurement (e.g., Miu \& Balteş, 2012; Naji et al., 2014). In one study, the behavioral component was measured (Labbé \& Grandjean, 2014). Interestingly, only four of these studies included the measurement of the aesthetic modality of emotions (e.g., Eerola et al., 2016); in two studies more than four modalities were measured, but in both they were reduced to the emotional dimensions of valence and arousal (Pesek, Strle, Kavčič, \& Marolt, 2017) or valence, arousal, and dominance (Daly et al., 2015).

In 13 studies, authors referred to music emotion or music-induced emotion in the Results and Discussion sections (e.g., Miu \& Balteş, 2012; Naji et al., 2014; Scherer, Trznadel, Fantini, \& Coutinho, 2019), even though only in seven of them the aesthetic modality of emotions was measured (e.g., Choppin et al., 2016; Labbé \& Grandjean, 2014; Miu \& Balteş, 2012). 


\section{DISCUSSION}

Although in the majority of the reviewed papers the authors declared that they explored emotions, in none of the studies was the full set of emotional properties analyzed, and none of them confirmed the induction of a wide range of modal emotions.

Action tendencies were explored sporadically. The results did not reveal behavioral tendencies distinctive for particular emotions, analogous to emotions experienced in everyday life. Two studies confirmed willingness to dance or move in response to music, which may be an effect of rhythm rather than music. In one study respondents reported a desire to constrain listening to the disliked music or to go on listening to the preferred songs (Thompson et al., 2019), which resembles reactions characteristic of affect (see Kolańczyk, Fila-Jankowska, Pawłowska-Fusiara, \& Sterczyński, 2004). Musically induced willingness to be active, observed in this research, seems to be rather a manifestation of a heightened level of energy.

Researchers investigated mimic expression only by measuring the activity of two muscles: corrugator and zygomaticus major, which in fact enables merely the assessment of positive/negative affect, not emotions (see Heller, Lapate, Mayer, \& Davidson, 2014; Larsen, Norris, \& Cacioppo, 2003; Tan et al., 2011; Topolinski \& Strack, 2015).

Based on the analyzed papers, it is impossible to outline neurophysiological response patterns specific to individual musical emotions. It is significant that chills are mentioned as a physical reaction in the context of music, because chills are not described in the context of any modal emotion. Konečni $(2008,2011$, 2013) includes them in a set of aesthetic reactions to music.

Neither the intentionality of emotions nor the importance of the emotioninducing situation/stimulus were explicitly investigated in the reviewed studies.

Our review confirmed the dominance of the dimensional model in research on emotional reactions to music, which is in line with the review carried out by Eerola and Vuoskoski (2013). Moreover, if modal emotions such as anger, guilt, or fear were analyzed, their frequency was very low and their intensity was, at most, moderate.

The use of dimensions in experiments and self-report studies is very simple and intuitive. However, it is doubtful whether this method of measurement is sufficient for the analysis of emotional reactions to music (Bigand, Vieillard, Madurell, Marozeau, \& Dacquet, 2005) and whether respondents prefer such tools for describing their experience (Chełkowska-Zacharewicz, 2018; Zentner 
et al., 2008). The dimensional models do not allow for making a distinction between experiences from the same affective quadrant, e.g. melancholy and boredom (Scherer, 2004) or anger and fear, because feelings mapped onto the affective space are a highly simplified representation of emotion (Evans \& Schubert, 2008) devoid of pivotal features (Briesemeister, Kuchinke, \& Jacobs, 2011; Lindquist, Siegel, Quigley, \& Barrett, 2013; Russell, 2003; Yik et al., 2011). In this context, a fundamental issue arises: How to interpret the situation when only two, three, or four modal emotion terms are used that belong to different affective quadrants and vary on the dimensions of affect? Do they refer to their modalities or are they only appellations pertaining to a high/low level of pleasantness and arousal? It is not possible to answer these questions unambiguously, but based the above observations we rather support the thesis that modal emotions in such situations should be classified as affect, not as modal emotions. An additional argument is the fact that feelings induced by music and modal "everyday" emotions may have the same name but different properties, as in the case of sadness. Musically induced sadness may refer to positive experiences (Eerola et al., 2016; Vuoskoski \& Eerola, 2017; Weth, Raab, \& Carbon, 2015), although in everyday life it is usually felt as something unpleasant.

Inference about the properties of emotions evoked by music is additionally hampered by the fact that music is often not the exclusive stimulus modifying current experience. In some studies it is difficult to determine to what extent the emotions are a result of the music itself, and what is the contribution of nonmusical factors such as social interactions (cf. Juslin et al., 2008) or song lyrics (cf. Thompson et al., 2019).

The above considerations do not support the thesis that music-induced emotional reactions are a short-lasting, intense, intentional, synchronized complex of organismic subsystems. However, the reviewed data do not deny this thesis either, and one cannot say that music definitely does not cause modal emotions. Future research might settle this issue, but only if certain methodological changes are introduced. In particular, it is necessary to expand the range of reactions measured concurrently: the quality, intensity, and duration of experiences must be verified as well as action tendencies, importance of the stimulus, and object orientation.

Our review is limited to papers analyzing emotions. To get a comprehensive and reliable picture of musically induced experiences, it is necessary to examine the conclusions derived from research focused explicitly on affect and mood. 


\section{CONCLUSIONS}

Some authors claim that music evokes the same emotional reactions as life events do, including basic ones. This suggestion implies that music may influence feelings, expressions, physiological reactions, and action tendencies, and that all these elements constitute a synchronized reaction that may be called a basic emotion. Such a perspective has been presented in a number of studies (Corrigall \& Schellenberg, 2013; Gingras, Marin, Puig-Waldmüller, \& Fitch, 2015; Hunter \& Schellenberg, 2010; Jaquet et al., 2014; Krahé et al., 2015). Considering the analyses presented in the review, we conclude that the idea of musicevoked modal/basic emotions has not been thoroughly delineated.

There is no evidence to claim that music activates emotions in their full form, characteristic of modal emotions. Probably the majority of music-induced experiences are narrowed down to affect. Their core is a combination of a particular level of arousal with the experience of pleasure or, less often, unpleasantness. This conclusion also applies to the situation when only two, three, or four modal emotional terms describing experiences of different levels of arousal and pleasure are used, for instance sad, anxious, happy, and calm. The analyzed data do not confirm the presence of specific action tendencies or the high intensity of these feelings, which are not a response to any personally significant event. In sum, it is more rational to presume that in this case modal emotions terms are used as labels of affect.

On the other hand, the total removal of the modal emotion terms would probably make it impossible to capture the qualitative differences between some of the music-induced experiences. For this reason, instead of modal/basic emotions, it is advisable to use a set of music-emotions or aesthetic emotions as phenomena complementary to affect. Affect seems to be the most common experience, aroused even when the music is only the background of daily activities. It likely does not demand reflection; according to Juslin and Västfjäll (2008), affect may be aroused by brain stem reflex, evaluative conditioning, or emotional contagion. Cespedes-Guevara and Eerola (2018) argue that music per se induces nothing more than affect. However, if one is focused on the structure of music or the quality of performance, which can be frequent when listening to a concert or during the experimental procedure, then aesthetic (e.g., awe) or epistemic (wonder) feelings (see: Coutinho \& Scherer, 2017) may appear due to musical expectancy or cognitive appraisal. The involvement of visual imagery or episodic memory (Juslin, \& Västfjäll, 2008) could generate music emotions such as tenderness, transcendence, or melancholy. Therefore, when the emotional reaction 
to music is in the center of our interest, we should explicitly relate to music or aesthetic emotions and measure the reaction accordingly, using dedicated domain-specific measurement tools.

The analyses presented above show the lack of discipline in the use of affective terms in the field of music psychology. An additional difficulty may be caused by the use of happy or sad feeling/emotion terms in reference to affect, emotion, and music emotion interchangeably, which is a rather natural consequence of linguistic deficiency. However, greater care in this domain could facilitate faster development of research in this field. In particular, we believe that, in research in which listeners focus on music, it is more appropriate to use categories/modalities of musical or aesthetic emotions. If music is only the background for other activities and is not in the center of the listener's attention, it seems more accurate to describe musically induced experiences as categories of affect. The list of music emotions and their full characteristics remains open.

The awareness of the distinction between modal emotion, affect, and music emotion might also be helpful for music composers, as well as for those who choose music for specific purposes, for example therapists or advertising specialists. The detailed information on the type of induced reaction and its components may allow for developing more precise means of influence in music-related domains.

\section{REFERENCES}

*Balteş, F. R., Avram, J., Miclea, M., \& Miu, A. C. (2011). Emotions induced by operatic music: Psychophysiological effects of music, plot, and acting. Brain and Cognition, 76(1), 146-157. https://doi.org/10.1016/j.bandc.2011.01.012

*Balteş, F. R., Miclea, M., \& Miu, A. C. (2012). Does everybody like Vivaldi's Four Seasons? Affective space and a comparison of music-induced emotions between musicians and nonmusicians. Cognition, Brain, Behavior, 16(1), 107-119.

*Balteș, F. R., \& Miu, A. C. (2014). Emotions during live music performance: Links with individual differences in empathy, visual imagery, and mood. Psychomusicology: Music, Mind, and Brain, 24(1), 58-65. https://doi.org/10.1037/pmu0000030

Barrett, L. F. (1998). Discrete emotions or dimensions? The role of valence focus and arousal focus. Cognition \& Emotion, 12(4), 579-599. https://doi.org/10.1080/026999398379574

Barrett, L. F. (2006). Solving the emotion paradox: Categorization and the experience of emotion. Personality and Social Psychology Review, 10(1), 20-46. https://doi.org/10.1207/s15327957 pspr1001_2

\footnotetext{
${ }^{1}$ The references marked with an asterisk $(*)$ were included in the review.
} 
Bicknell, J. (2007). Explaining strong emotional responses to music. Sociality and intimacy. Journal of Consciousness Studies, 14(12), 5-23.

Bigand, E., Vieillard, S., Madurell, F., Marozeau, J., \& Dacquet, A. (2005). Multidimensional scaling of emotional responses to music: The effect of musical expertise and of the duration of the excerpts. Cognition \& Emotion, 19(8), 1113-1139. https://doi.org/10.1080/02699930 500204250

Briesemeister, B. B., Kuchinke, L., \& Jacobs, A. M. (2011). Discrete emotion effects on lexical decision response times. PLoS ONE, 6(8), e23743. https://doi.org/10.1371/journal.pone. 0023743

Cespedes-Guevara, J., \& Eerola, T. (2018). Music communicates affects, not basic emotionsA constructionist account of attribution of emotional meanings to music. Frontiers in Psychology, 9, 215. https://doi.org/10.3389/fpsyg.2018.00215

Chełkowska-Zacharewicz, M. (2018). Preferences for different emotional response scale types in music experience. Poster presented at the 15th International Conference on Music Perception and Cognition and at the 10th triennial conference of the European Society for the Cognitive Sciences of Music in Graz, Austria.

${ }^{*}$ Cheng, F.-F., Wu, C.-S., \& Yen, D. C. (2009). The effect of online store atmosphere on consumer's emotional responses-An experimental study of music and colour. Behaviour \& Information Technology, 28(4), 323-334. https://doi.org/10.1080/01449290701770574

Choppin, S., Trost, W., Dondaine, T., Millet, B., Drapier, D., Vérin, M., Robert, G., \& Grandjean, D. (2016). Alteration of complex negative emotions induced by music in euthymic patients with bipolar disorder. Journal of Affective Disorders, 191, 15-23. https://doi.org/10.1016/ j.jad.2015.10.063

Corrigall, K. A., \& Schellenberg, E. G. (2013). Music: The language of emotion. In C. Mohiyeddini, M. Eysenck, \& S. Bauer (Eds.), Psychology of emotions, motivations and actions. Handbook of psychology of emotions: Recent theoretical perspectives and novel empirical findings (vol. 2, pp. 299-325). Hauppauge: Nova Science Publishers.

Coutinho, E., \& Scherer, K. R. (2017). Introducing the GEneva Music-Induced Affect Checklist (GEMIAC): A brief instrument for the rapid assessment of musically induced emotions. Music Perception: An Interdisciplinary Journal, 34(4), 371-386. https://doi.org/10.1525/mp. 2017.34.4.371

*Daly, I., Malik, A., Hwang, F., Roesch, E., Weaver, J., Kirke, A., Williams, D., Miranda, E., \& Nasuto, S. J. (2014). Neural correlates of emotional responses to music: An EEG study. Neuroscience Letters, 573, 52-57. https://doi.org/10.1016/j.neulet.2014.05.003

*Daly, I., Williams, D., Hallowell, J., Hwang, F., Kirke, A., Malik, A., Weaver, J., Miranda, E., \& Nasuto, S. J. (2015). Music-induced emotions can be predicted from a combination of brain activity and acoustic features. Brain and Cognition, 101, 1-11. https://oi.org/10.1016/ j.bandc.2015.08.003

Damasio, A. R. (2005). Descartes'error: Emotion, reason, and the human brain. London: Penguin.

Davidson, R. J. (1994). Complexities in the search for emotion-specific physiology. In P. Ekman \& R. J. Davidson (Eds.), The nature of emotion: Fundamental questions (pp. 237-242). New York, NY, US: Oxford University Press.

*Dibben, N. (2004). The role of peripheral feedback in emotional experience with music. Music Perception: An Interdisciplinary Journal, 22(1), 79-115. https://doi.org/10.1525/mp.2004. 22.1.79 
Eerola, T., \& Vuoskoski, J. K. (2011). A comparison of the discrete and dimensional models of emotion in music. Psychology of Music, 39(1), 18-49. https://doi.org/10.1177/030573561 0362821

Eerola, T., \& Vuoskoski, J. K. (2013). A review of music and emotion studies: Approaches, emotion models, and stimuli. Music Perception: An Interdisciplinary Journal, 30(3), 307-340. https://doi.org/10.1525/mp.2012.30.3.307

*Eerola, T., Vuoskoski, J. K., \& Kautiainen, H. (2016). Being moved by unfamiliar sad music is associated with high empathy. Frontiers in Psychology, 7, 1176. https://doi.org/10.3389/ fpsyg.2016.01176

*Egermann, H., \& McAdams, S. (2013). Empathy and emotional contagion as a link between recognized and felt emotions in music listening. Music Perception, 31(2), 139-156. https://doi.org/10.1525/mp.2013.31.2.139

*Egermann, H., Nagel, F., Altenmüller, E., \& Kopiez, R. (2009). Continuous measurement of musically-induced emotion: A web experiment. International Journal of Internet Science, 4(1), 4-20.

*Egermann, H., Sutherland, M. E., Grewe, O., Nagel, F., Kopiez, R., \& Altenmüller, E. (2011). Does music listening in a social context alter experience? A physiological and psychological perspective on emotion. Musicae Scientiae, 15(3), 307-323. https://doi.org/10.1177/1029 864911399497

Ekman, P. (1992). An argument for basic emotions. Cognition and Emotion, 6(3-4), 169-200.

Ekman, P. (1993). Facial expression and emotion. American Psychologist, 4(48), 384-392.

Ekman, P. (1994). Moods, emotions, and traits. In P. Ekman \& R. J. Davidson (Eds.), The nature of emotion: Fundamental questions (pp. 56-58). New York, NY, US: Oxford University Press.

Ekman, P. (1999). Facial expressions. In T. Power \& P. Power (Eds.), Handbook of cognition and emotion (pp. 301-320). Chichester, UK, \& New York, NY, US: Wiley.

*Etzel, J. A., Johnsen, E. L., Dickerson, J., Tranel, D., \& Adolphs, R. (2006). Cardiovascular and respiratory responses during musical mood induction. International Journal of Psychophysiology, 61(1), 57-69. https://doi.org/10.1016/j.ijpsycho.2005.10.025

*Evans, P., \& Schubert, E. (2008). Relationships between expressed and felt emotions in music. Musicae Scientiae, 12(1), 75-99. https://doi.org/10.1177/102986490801200105

Fehr, B., \& Russell, J. A. (1984). Concept of emotion viewed from a prototype perspective. Journal of Experimental Psychology: General, 113(3), 464-486.

Frijda, N. (1988). The laws of emotion. American Psychologist, 43(5), 349-358.

Frijda, N. (1994). Varieties of affect: Emotions and episodes, moods, and sentiments. In P. Ekman \& R. J. Davidson (Eds.), The nature of emotion, fundamental questions (pp. 59-67). Oxford: Oxford University Press.

Gabrielsson, A. (2001). Emotion perceived and emotion felt: Same or different?. Musicae Scientiae, Spec Issue 2001-2002, 123-147. https://doi.org/10.1177/10298649020050S105

Gabrielsson, A. (2011). Strong experiences with music: Music is much more than just music. Oxford: Oxford University Press.

Gabrielsson, A., \& Wik, S. L. (2003). Strong experiences related to music: A descriptive system. Musicae Scientiae, 7(2), 157-217. https://doi.org/10.1177/102986490300700201

*Gingras, B., Marin, M. M., Puig-Waldmüller, E., \& Fitch, W. T. (2015). The eye is listening: Music-induced arousal and individual differences predict pupillary responses. Frontiers in Human Neuroscience, 9, 619. https://doi.org/10.3389/fnhum.2015.00619 
Goldsmith, H. H. (1994). Parsing the emotional domain from a development perspective. In P. Ekman \& R. J. Davidson (Eds.), The nature of emotion: Fundamental questions (pp. 6873). New York, NY, US: Oxford University.

*Gomez, P., \& Danuser, B. (2007). Relationships between musical structure and psychophysiological measures of emotion. Emotion, 7(2), 377-387. https://doi.org/10.1037/1528 $-3542.7 .2 .377$

Heller, A. S., Lapate, R. C., Mayer, K. E., \& Davidson, R. J. (2014). The face of negative affect: Trial-by-trial corrugator responses to negative pictures are positively associated with amygdala and negatively associated with ventromedial prefrontal cortex activity. Journal of Cognitive Neuroscience, 26(9), 2102-2110. https://doi.org/10.1162/jocn_a_00622

*Hunter, P. G., \& Schellenberg, E. G. (2010). Music and emotion. In M. Riess Jones, R. R. Fay, \& A. N. Popper (Eds.), Music perception (vol. 36, pp. 129-164). New York, NY, US: Springer New York.

Hunter, P. G., Schellenberg, E. G., \& Schimmack, U. (2010). Feelings and perceptions of happiness and sadness induced by music: Similarities, differences, and mixed emotions. Psychology of Aesthetics, Creativity, and the Arts, 4(1), 47-56. https://doi.org/10.1037/ a0016873

Izard, C. E. (2007). Basic emotions, natural kinds, emotion schemas, and a new paradigm. Perspectives on Psychological Science, 2(3), 260-280. https://doi.org/10.1111/j.17456916.2007.00044.x

Izard, C. E. (2009). Emotion theory and research: Highlights, unanswered questions, and emerging issues. Annual Review of Psychology, 60(1), 1-25. https://doi.org/10.1146/annurev.psych. 60.110707.163539

*Jaquet, L., Danuser, B., \& Gomez, P. (2014). Music and felt emotions: How systematic pitch level variations affect the experience of pleasantness and arousal. Psychology of Music, 42(1), 5170. https://doi.org/10.1177/0305735612456583

*Johnsen, E. L., Tranel, D., Lutgendorf, S., \& Adolphs, R. (2009). A neuroanatomical dissociation for emotion induced by music. International Journal of Psychophysiology, 72(1), 24-33. https://doi.org/10.1016/j.ijpsycho.2008.03.011

Johnson-Laird, P. N., \& Oatley, K. (1988). Are there only two primitive emotions? A reply to Frijda. Cognition \& Emotion, 2(2), 89-93.

Johnson-Laird, P. N., \& Oatley, K. (1989). The language of emotions: An analysis of a semantic field. Cognition \& Emotion, 3(2), 81-123.

*Juslin P. N., Barradas, G., \& Eerola, T. (2015). From sound to significance: Exploring the mechanisms underlying emotional reactions to music. The American Journal of Psychology, 128(3), 281-304. https://doi.org/10.5406/amerjpsyc.128.3.0281

*Juslin, P., Harmat, L., \& Eerola, T. (2014). What makes music emotionally significant? Exploring the underlying mechanisms. Psychology of Music, 42(4), 599-623. https://doi.org/10.1177/ 0305735613484548

*Juslin, P., Liljeström, S., Västfjäll, D., Barradas, G., \& Silva, A. (2008). An experience sampling study of emotional reactions to music: Listener, music, and situation. Emotion, 8(5), 668-683. https://doi.org/10.1037/a0013505

Juslin, P. N., \& Västfjäll, D. (2008). Emotional responses to music: The need to consider underlying mechanisms. Behavioral and Brain Sciences, 31(05), 559-621. https://doi.org/ $10.1017 / \mathrm{S} 0140525 \mathrm{X} 08005293$ 
*Kawakami, A., Furukawa, K., Katahira, K., \& Okanoya, K. (2013). Sad music induces pleasant emotion. Frontiers in Psychology, 4(June), 311. https://doi.org/10.3389/fpsyg.2013.00311

*Kawakami, A., Kiyoshi, F., Katahira, K., Kamiyama, K., \& Okanoya, K. (2013). Relations between musical structures and perceived and felt emotions. Music Perception: An Interdisciplinary Journal, 30(4), 407-417. https://doi.org/10.1525/mp.2013.30.4.407

Keltner, D., \& Gross, J. J. (1999). Functional accounts of emotions. Cognition \& Emotion, 13(5), 467-480.

Keltner, D., \& Haidt, J. (2001). Social functions of emotions. In T. Mayne \& G. Bonanno (Eds.), Emotions: Current issues and future directions (pp. 192-213). New York, NY, US: Guilford Press.

Kolańczyk, A., Fila-Jankowska, A., Pawłowska-Fusiara, M., \& Sterczyński, R. (2004). Serce $w$ rozumie: afektywne podstawy orientacji $w$ otoczeniu [Heart in mind: The affective basis of orientation in the environment]. Gdańsk: Gdańskie Wydawnictwo Psychologiczne.

Konečni, V. J. (2008). A skeptical position on "musical emotions" and an alternative proposal. Behavioral and Brain Sciences, 31(05). https://doi.org/10.1017/S0140525X08005372

Konečni, V. J. (2011). Aesthetic trinity theory and the sublime. Philosophy Today, 55(1), 64-73. https/doi.org/10.5840/philtoday201155162

Konečni, V. J. (2013). Music, affect, method, data: Reflections on the Carroll versus Kivy debate. The American Journal of Psychology, 126(2), 179-195. https://doi.org/10.5406/amerjpsyc. 126.2.0179

*Kopec, J., Hillier, A., \& Frye, A. (2014). The valency of music has different effects on the emotional responses of those with autism spectrum disorders and a comparison group. Music Perception: An Interdisciplinary Journal, 31(5), 436-443. https://doi.org/10.1525/mp.2014. 31.5.436

Kowalska, M., \& Wróbel, M. (2017). Basic emotions. In V. Zeigler-Hill \& T. K. Shackelford (Eds.), Encyclopedia of personality and individual differences (pp. 1-6). Cham, Switzerland: Springer International Publishing.

*Krahé, C., Hahn, U., \& Whitney, K. (2015). Is seeing (musical) believing? The eye versus the ear in emotional responses to music. Psychology of Music, 43(1), 140-148. https://doi.org/ $10.1177 / 0305735613498920$

*Kreutz, G., Ott, U., Teichmann, D., Osawa, P., \& Vaitl, D. (2008). Using music to induce emotions: Influences of musical preference and absorption. Psychology of Music, 36(1), 101126. https://doi.org/10.1177/0305735607082623

*Krumhansl, C. L. (1997). An exploratory study of musical emotions and psychophysiology. Canadian Journal of Experimental Psychology / Revue canadienne de psychologie expérimentale, 51(4), 336-353. https://doi.org/10.1037/1196-1961.51.4.336

*Labbé, C., Glowinski, D., \& Grandjean, D. (2016). The effect of ensemble and solo performance on affective experiences induced by music. Psychology of Music, 45(4), 600-608. https://doi.org/10.1177/0305735616659551

*Labbé, C., \& Grandjean, D. (2014). Musical emotions predicted by feelings of entrainment. Music Perception: An Interdisciplinary Journal, 32(2), 170-185. https://doi.org/10.1525/ mp.2014.32.2.170

*Ladinig, O., \& Schellenberg, E. G. (2012). Liking unfamiliar music: Effects of felt emotion and individual differences. Psychology of Aesthetics, Creativity, and the Arts, 6(2), 146-154. https://doi.org/10.1037/a0024671 
Larsen, J. T., Norris, C. J., \& Cacioppo, J. T. (2003). Effects of positive and negative affect on electromyographic activity over zygomaticus major and corrugator supercilii. Psychophysiology, 40(5), 776-785.

*Larsen, J. T., \& Stastny, B. J. (2011). It's a bittersweet symphony: Simultaneously mixed emotional responses to music with conflicting cues. Emotion, 11(6), 1469-1473. https://doi.org/10.1037/a0024081

Lindquist, K. A., Siegel, E. H., Quigley, K. S., \& Barrett, L. F. (2013). The hundred-year emotion war: Are emotions natural kinds or psychological constructions? Comment on Lench, Flores, and Bench (2011). Psychological Bulletin, 139(1), 255-263. https://doi.org/10.1037/a0029038

*Lundqvist, L.-O., Carlsson, F., Hilmersson, P., \& Juslin, P. N. (2009). Emotional responses to music: Experience, expression, and physiology. Psychology of Music, 37(1), 61-90. https://doi.org/10.1177/0305735607086048

*Marin, M. M., Gingras, B., \& Bhattacharya, J. (2012). Crossmodal transfer of arousal, but not pleasantness, from the musical to the visual domain. Emotion, 12(3), 618-631. https://doi.org/10.1037/a0025020

Matsumoto, D., Keltner, D., Shiota, M., Frank, M., \& O'Sullivan, M. (2008). What's in a face? Facial expressions as signals of discrete emotions. In M. Lewis, J. Haviland-Jones, \& L. F. Barrett (Eds.), Handbook of emotions (pp. 211-234). New York, NY, US: Guilford Press.

*Miu, A. C., \& Balteş, F. R. (2012). Empathy manipulation impacts music-induced emotions: A psychophysiological study on opera. PLoS ONE, 7(1), e30618. https://doi.org/10.1371/ journal.pone. 0030618

*Mori, K., \& Iwanaga, M. (2014). Pleasure generated by sadness: Effect of sad lyrics on the emotions induced by happy music. Psychology of Music, 42(5), 643-652. https://doi.org/ $10.1177 / 0305735613483667$

*Naji, M., Firoozabadi, M., \& Azadfallah, P. (2014). Classification of music-induced emotions based on information fusion of forehead biosignals and electrocardiogram. Cognitive Computation, 6(2), 241-252. https://doi.org/10.1007/s12559-013-9239-7

*Olsen, K. N., \& Stevens, C. J. (2013). Psychophysiological response to acoustic intensity change in a musical chord. Journal of Psychophysiology, 27(1), 16-26. https://doi.org/10.1027/0269$8803 / \mathrm{a} 000082$

*Pesek, M., Strle, G., Kavčič, A., \& Marolt, M. (2017). The Moodo dataset: Integrating user context with emotional and color perception of music for affective music information retrieval. Journal of New Music Research, 46(3), 246-260. https://doi.org/10.1080/09298215. 2017.1333518

Russell, J. A. (2003). Core affect and the psychological construction of emotion. Psychological Review, 110(1), 145-172. https://doi.org/10.1037/0033-295x.110.1.145

Sacharin, V., Schlegel, K., \& Scherer, K. R. (2012). Geneva Emotion Wheel rating study (Report). University of Geneva, Swiss Center for Affective Sciences.

Salimpoor, V. N., Benovoy, M., Larcher, K., Dagher, A., \& Zatorre, R. J. (2011). Anatomically distinct dopamine release during anticipation and experience of peak emotion to music. Nature Neuroscience, 14(2), 257-262. https://doi.org/10.1038/nn.2726

*Salimpoor, V. N., Benovoy, M., Longo, G., Cooperstock, J. R., \& Zatorre, R. J. (2009). The rewarding aspects of music listening are related to degree of emotional arousal. PLOS ONE, 4(10), e7487. https://doi.org/10.1371/journal.pone.0007487 
*Sammler, D., Grigutsch, M., Fritz, T., \& Koelsch, S. (2007). Music and emotion: Electrophysiological correlates of the processing of pleasant and unpleasant music. Psychophysiology, 44(2), 293-304. https://doi.org/10.1111/j.1469-8986.2007.00497.x

Scherer, K. R. (2004). Which emotions can be induced by music? What are the underlying mechanisms? And how can we measure them? Journal of New Music Research, 33(3), 239251. https://doi.org/10.1080/0929821042000317822

Scherer, K. R. (2005). What are emotions? And how can they be measured? Social Science Information, 44(4), 695-729. https://doi.org/10.1177/053901840505821

Scherer, K. R., Shuman, V., Fontaine, J. R. J., \& Soriano, C. (2013). The GRID meets the Wheel: Assessing emotional feeling via self-report1. In J. R. J. Fontaine, K. R. Scherer, \& C. Soriano (Eds.), Components of emotional meaning: A sourcebook (pp. 281-298). Oxford: Oxford University Press. https://doi.org/10.1093/acprof:oso/9780199592746.003.0019

*Scherer, K. R., Trznadel, S., Fantini, B., \& Coutinho, E. (2019). Assessing emotional experiences of opera spectators in situ. Psychology of Aesthetics, Creativity, and the Arts, 13(3), 244-258. https://doi.org/10.1037/aca0000163 [Access online first].

*Schubert, E. (2007). The influence of emotion, locus of emotion and familiarity upon preference in music. Psychology of Music, 35(3), 499-515. https://doi.org/10.1177/0305735607072657

*Schubert, E. (2010). Affective, evaluative, and collative responses to hated and loved music. Psychology of Aesthetics, Creativity, and the Arts, 4(1), 36-46. https://doi.org/10.1037/ a0016316

*Schubert, E. (2013). Loved music can make a listener feel negative emotions. Musicae Scientiae, 17(1), 11-26. https://doi.org/10.1177/1029864912461321

Shaver, P. R., Morgan, H. J., \& Wu, S. (1996). Is love a "basic" emotion? Personal Relationships, 3(1), 81-96. https://doi.org/10.1111/j.1475-6811.1996.tb00105.x

Shaver, P. R., Schwartz, J., Kirson, D., \& O’Connor, C. (1987). Emotion knowledge: Further exploration of a prototype approach. Journal of Personality and Social Psychology, 52(6), 1061-1086. https://doi.org/10.1037//0022-3514.52.6.1061

*Song, Y., Dixon, S., Pearce, M. T., \& Halpern, A. R. (2016). Perceived and induced emotion responses to popular music: Categorical and dimensional models. Music Perception: An Interdisciplinary Journal, 33(4), 472-492. https://doi.org/10.1525/mp.2016.33.4.472

*Tabei, K. (2015). Inferior frontal gyrus activation underlies the perception of emotions, while precuneus activation underlies the feeling of emotions during music listening. Behavioural Neurology, 1-6. https://doi.org/10.1155/2015/529043

Tan, J.-W., Walter, S., Scheck, A., Hrabal, D., Hoffmann, H., Kessler, H., \& Traue, H. C. (2011). Facial electromyography (fEMG) activities in response to affective visual stimulation. 2011 IEEE Workshop on Affective Computational Intelligence (WACI), 1-5. https://doi.org/ 10.1109/WACI.2011.5953144

*Thompson, W. F., Geeves, A. M., \& Olsen, K. N. (2019). Who enjoys listening to violent music and why? Psychology of Popular Media Culture, 8(3), 218-232. https://doi.org/10.1037/ ppm0000184 [Access online first].

Topolinski, S., \& Strack, F. (2015). Corrugator activity confirms immediate negative affect in surprise. Frontiers in Psychology, 6, 134. https://doi.org/10.3389/fpsyg.2015.00134

*Trost, W., Ethofer, T., Zentner, M., \& Vuilleumier, P. (2011). Mapping aesthetic musical emotions in the brain. Cerebral Cortex, 22(12), 2769-2783. https://doi.org/10.1093/cercor/bhr353 
*Trost, W., Frühholz, S., Cochrane, T., Cojan, Y., \& Vuilleumier, P. (2015). Temporal dynamics of musical emotions examined through intersubject synchrony of brain activity. Social Cognitive and Affective Neuroscience, 10(12), 1705-1721. https://doi.org/10.1093/scan/nsv060

*Vásquez-Rosati, A. (2017). Body awareness to recognize feelings. Constructivist Foundations, 12(2), 219-226.

*Vernooij, E., Orcalli, A., Fabbro, F., \& Crescentini, C. (2016). Listening to the Shepard-Risset glissando: The relationship between emotional response, disruption of equilibrium, and personality. Frontiers in Psychology, 7, 300. https://doi.org/10.3389/fpsyg.2016.00300

*Vuoskoski, J. K., \& Eerola, T. (2011). Measuring music-induced emotion: A comparison of emotion models, personality biases, and intensity of experiences. Musicae Scientiae, 15(2), 159-173. https://doi.org/10.1177/102986491101500203

*Vuoskoski, J. K., \& Eerola, T. (2017). The pleasure evoked by sad music is mediated by feelings of being moved. Frontiers in Psychology, 8, 439. https://doi.org/10.3389/fpsyg.2017.00439

*Vuoskoski, J. K., Gatti, E., Spence, C., \& Clarke, E. F. (2016). Do visual cues intensify the emotional responses evoked by musical performance? A psychophysiological investigation. Psychomusicology: Music, Mind, and Brain, 26(2), 179-188. https://doi.org/10.1037/ pmu0000142

*Vuoskoski, J. K., Thompson, W. F., McIlwain, D., \& Eerola, T. (2012). Who enjoys listening to sad music and why? Music Perception, 29(3), 311-317. https://doi.org/10.1525/mp.2012. 29.3.311

Watson, D., \& Clark, L. A. (1994). Emotions, moods, traits, and temperaments: Conceptual distinctions and empirical findings. In P. Ekman \& R. J. Davidson (Eds.), The nature of emotion: Fundamental questions (pp. 89-93). New York, NY, US: Oxford University Press.

Weth, K., Raab, M. H., \& Carbon, C.-C. (2015). Investigating emotional responses to self-selected sad music via self-report and automated facial analysis. Musicae Scientiae, 19(4), 412-432. https://doi.org/10.1177/1029864915606796

*Wheeler, B. L., Sokhadze, E., Baruth, J., Behrens, G. A., \& Quinn, C. F. (2011). Musically induced emotions: Subjective measures of arousal and valence. Music and Medicine, 3(4), 224-233. https://doi.org/10.1177/1943862111407513

*Wu, X., \& Sun, G. (2018). Music-induced emotions and musical regulation and emotion improvement based on EEG technology. NeuroQuantology, 16(6), 379-384. https://doi.org/ 10.14704/nq.2018.16.6.1593

*Yamauchi, T., \& Xiao, K. (2018). Reading emotion from mouse cursor motions: Affective computing approach. Cognitive Science, 42(3), 771-819. https://doi.org/10.1111/cogs.12557

Yik, M., Russell, J. A., \& Steiger, J. H. (2011). A 12-point circumplex structure of core affect. Emotion, 11(4), 705-731. https://doi.org/10.1037/a0023980

*Zentner, M., Grandjean, D., \& Scherer, K. R. (2008). Emotions evoked by the sound of music: Characterization, classification, and measurement. Emotion, 8(4), 494-521. https://doi.org/ $10.1037 / 1528-3542.8 .4 .494$ 


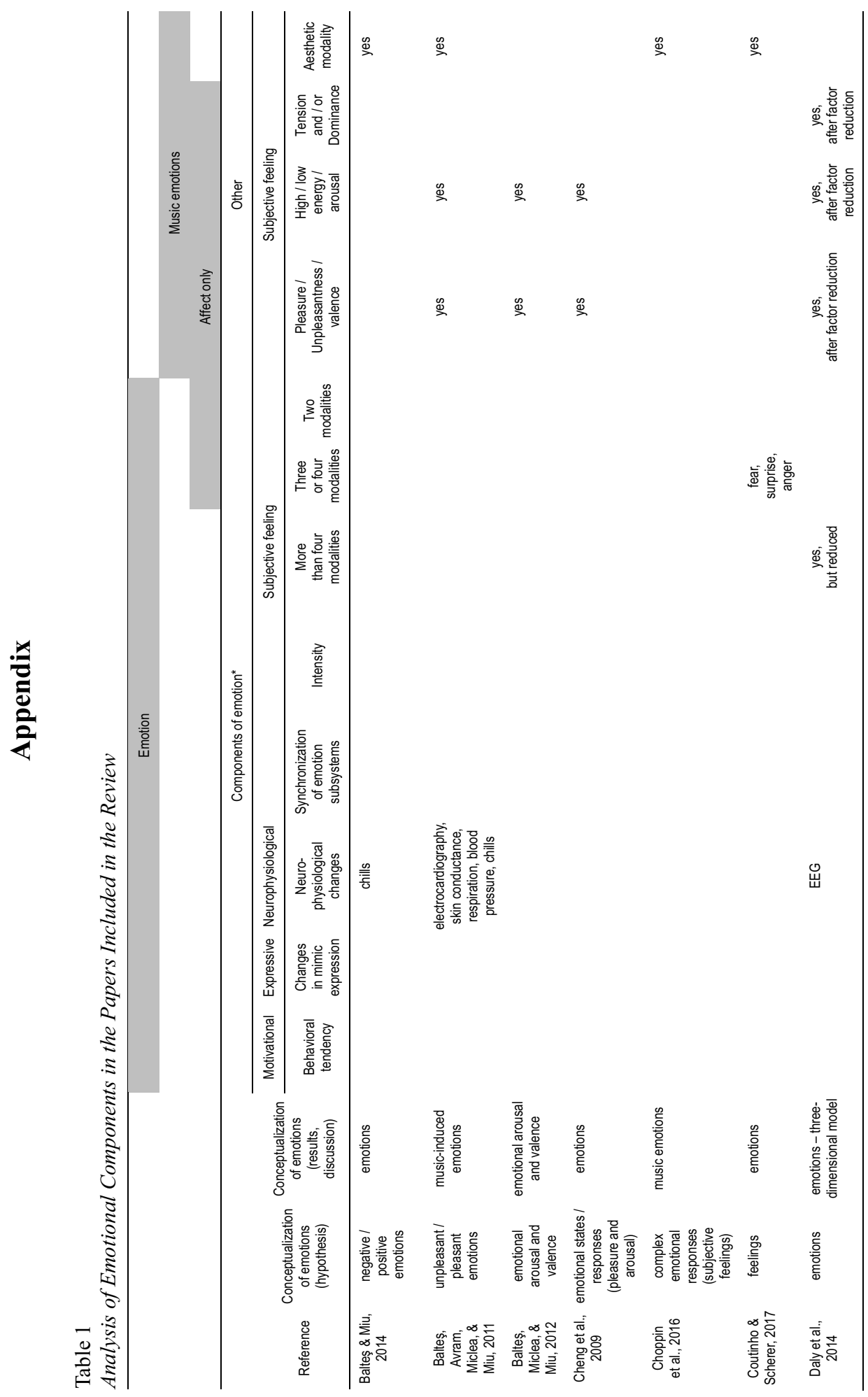




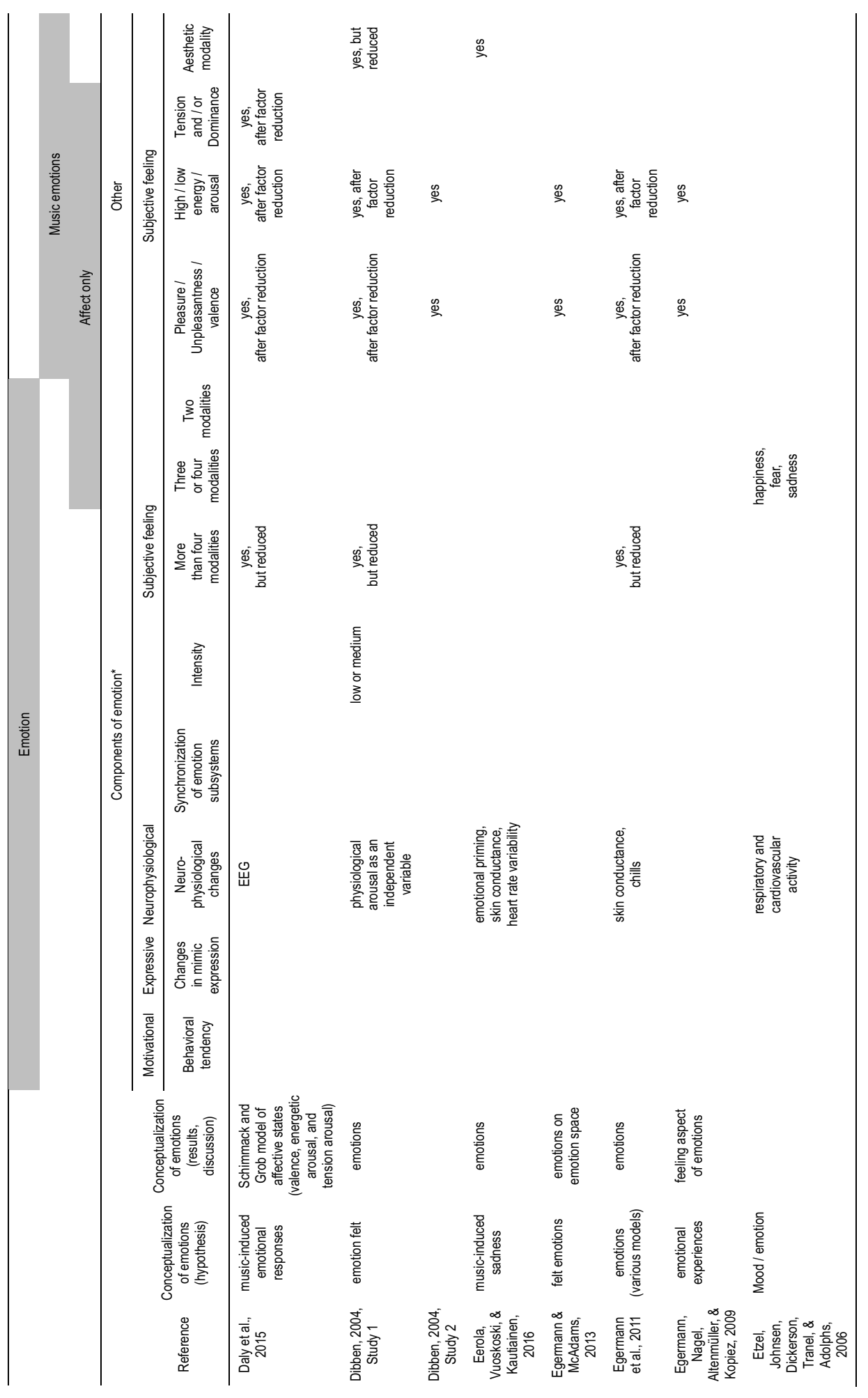




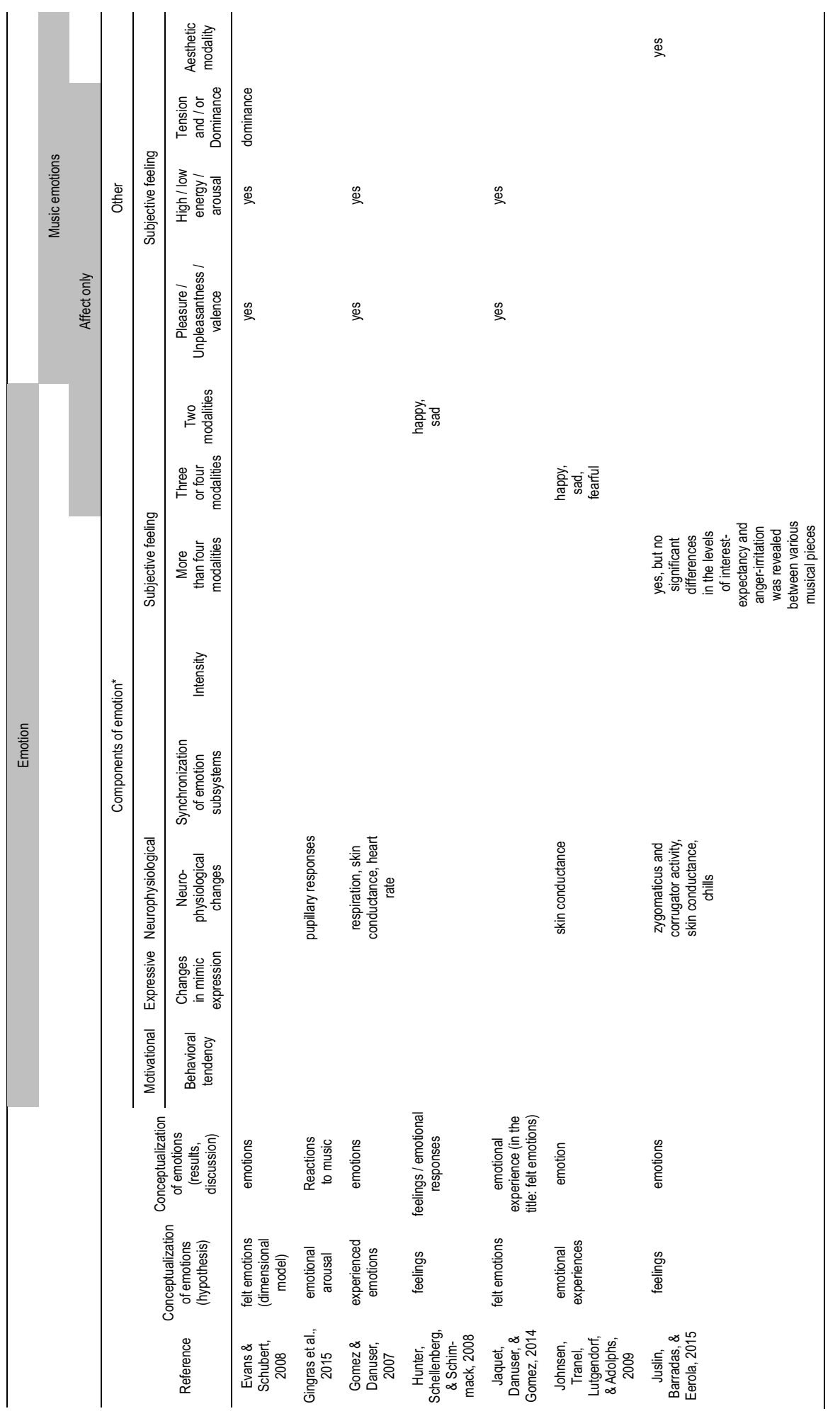




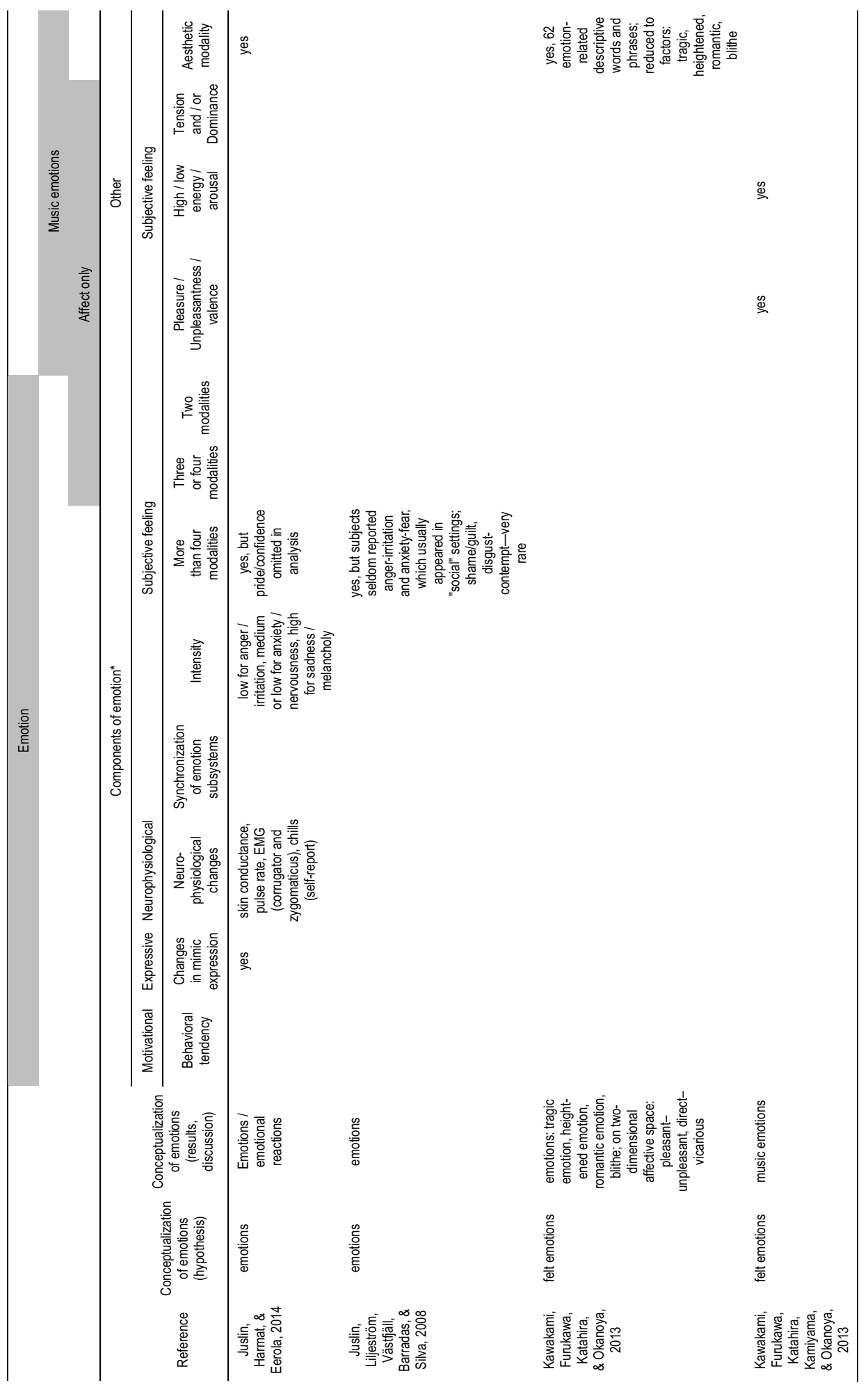




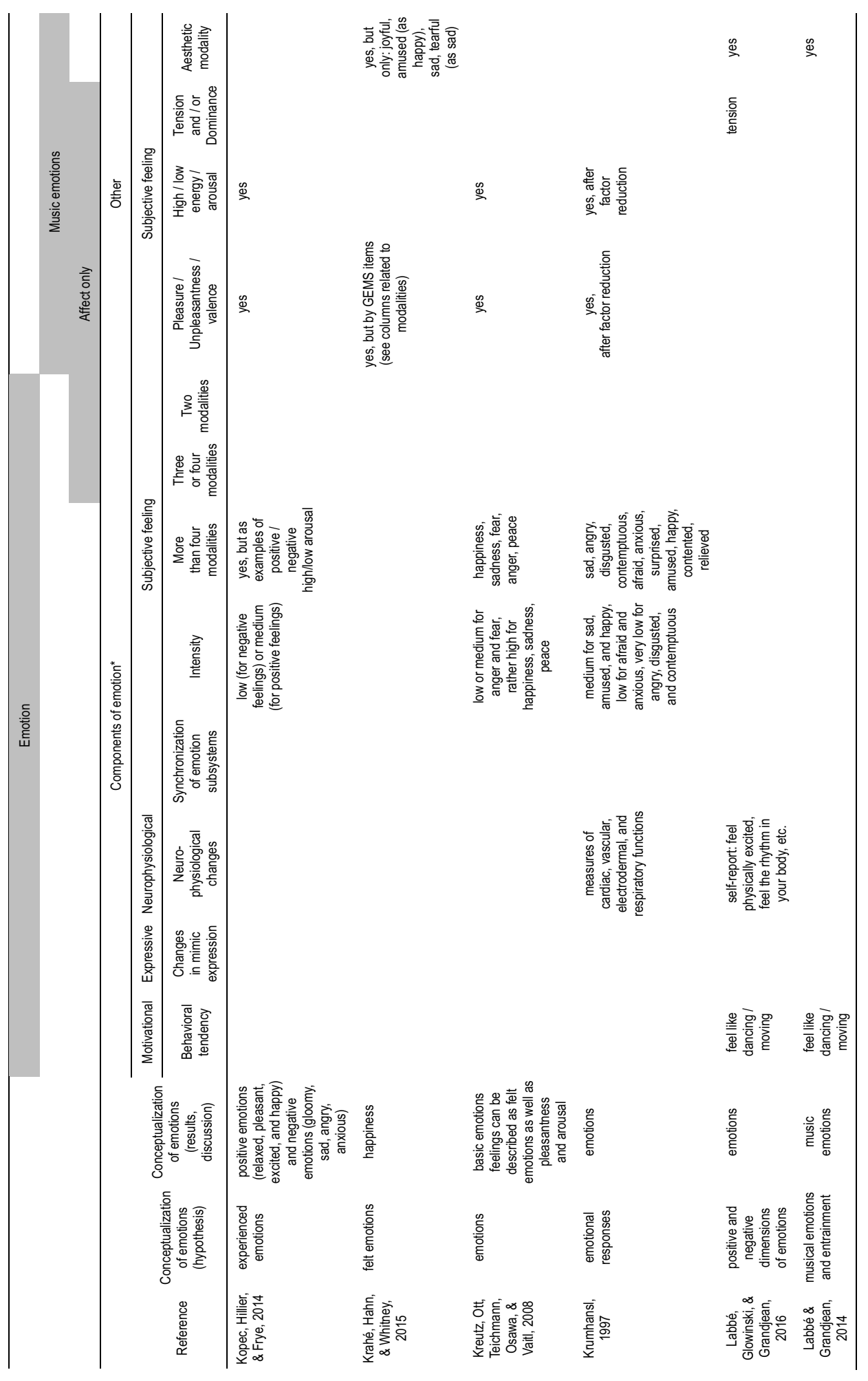




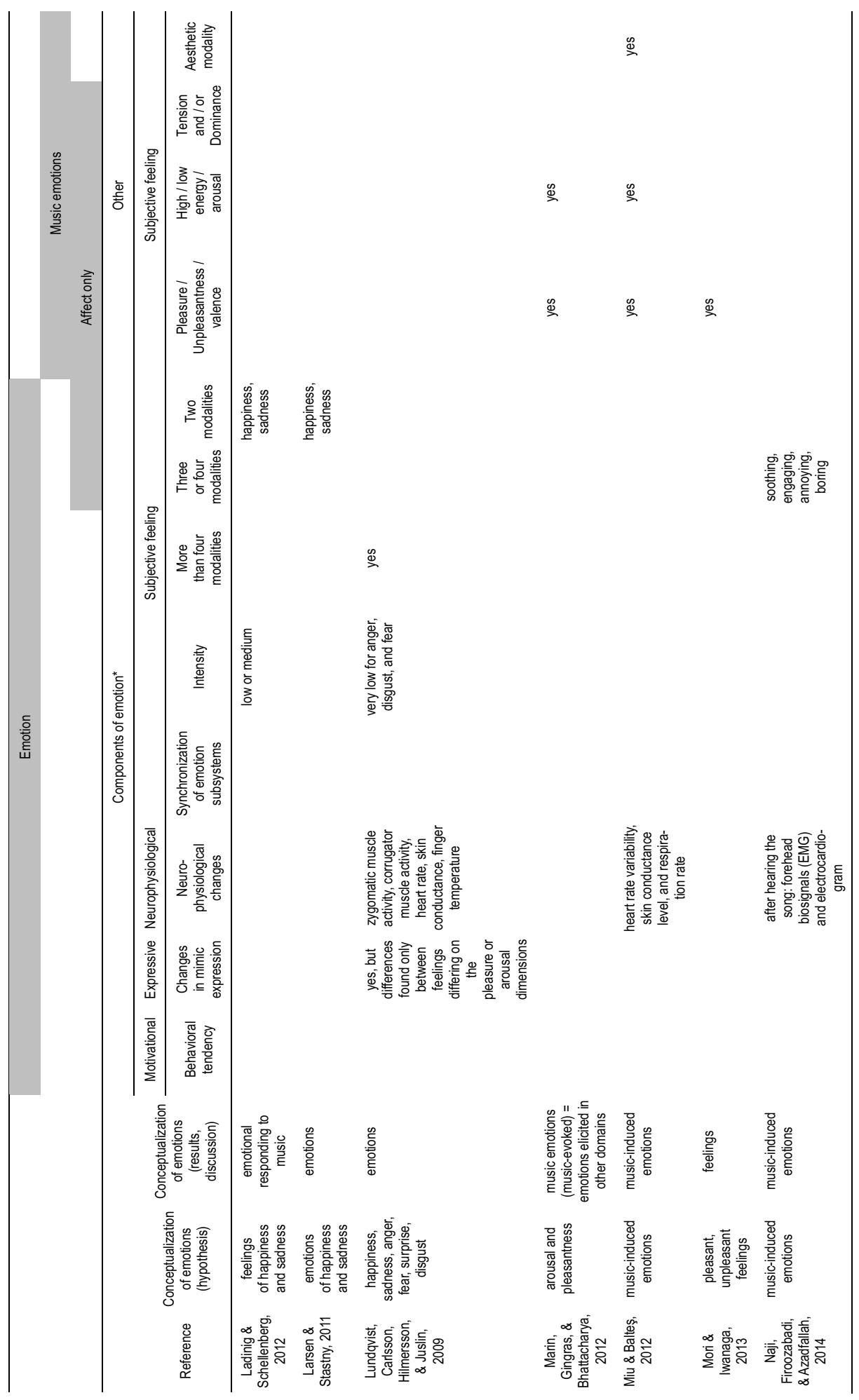




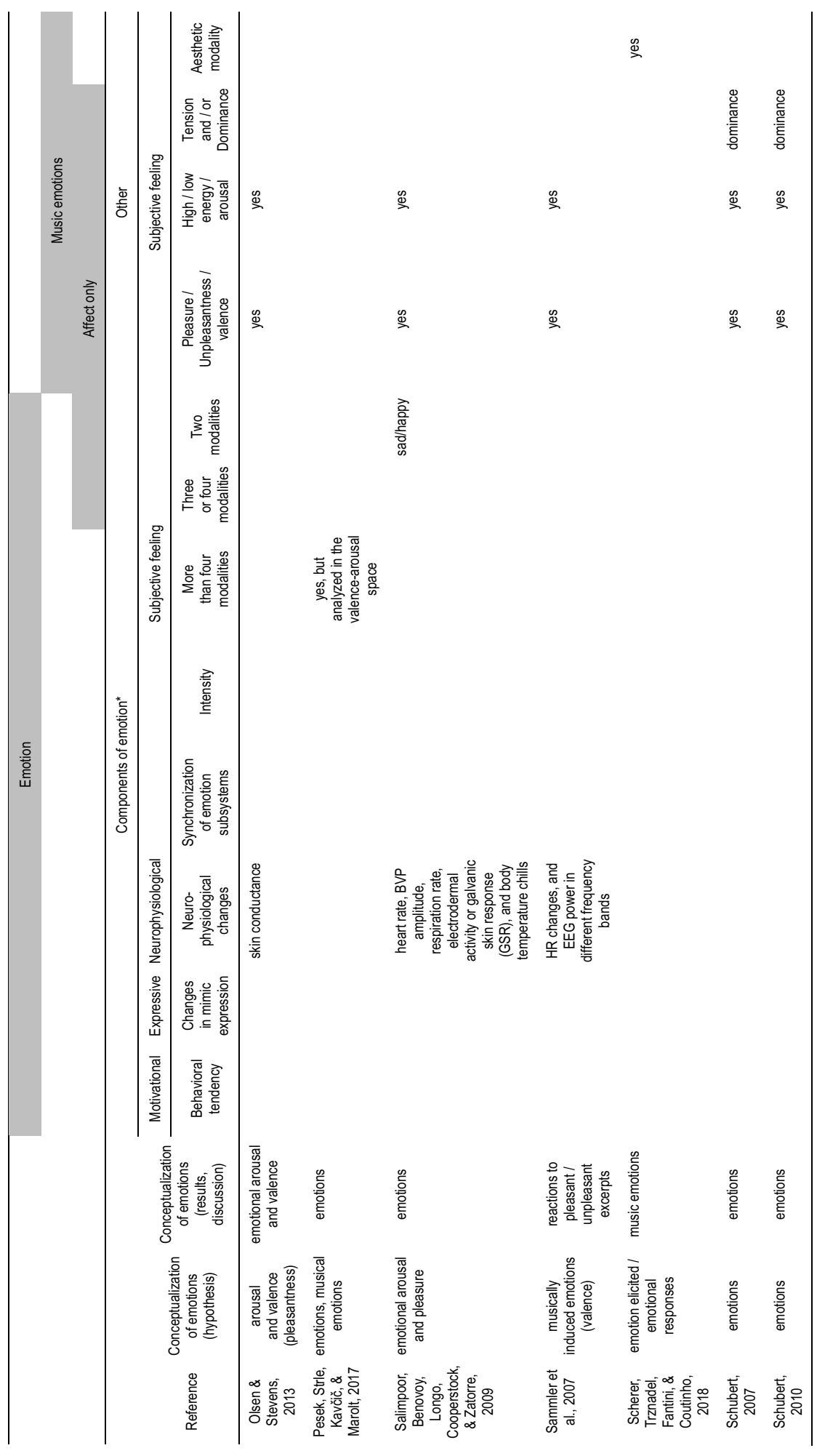




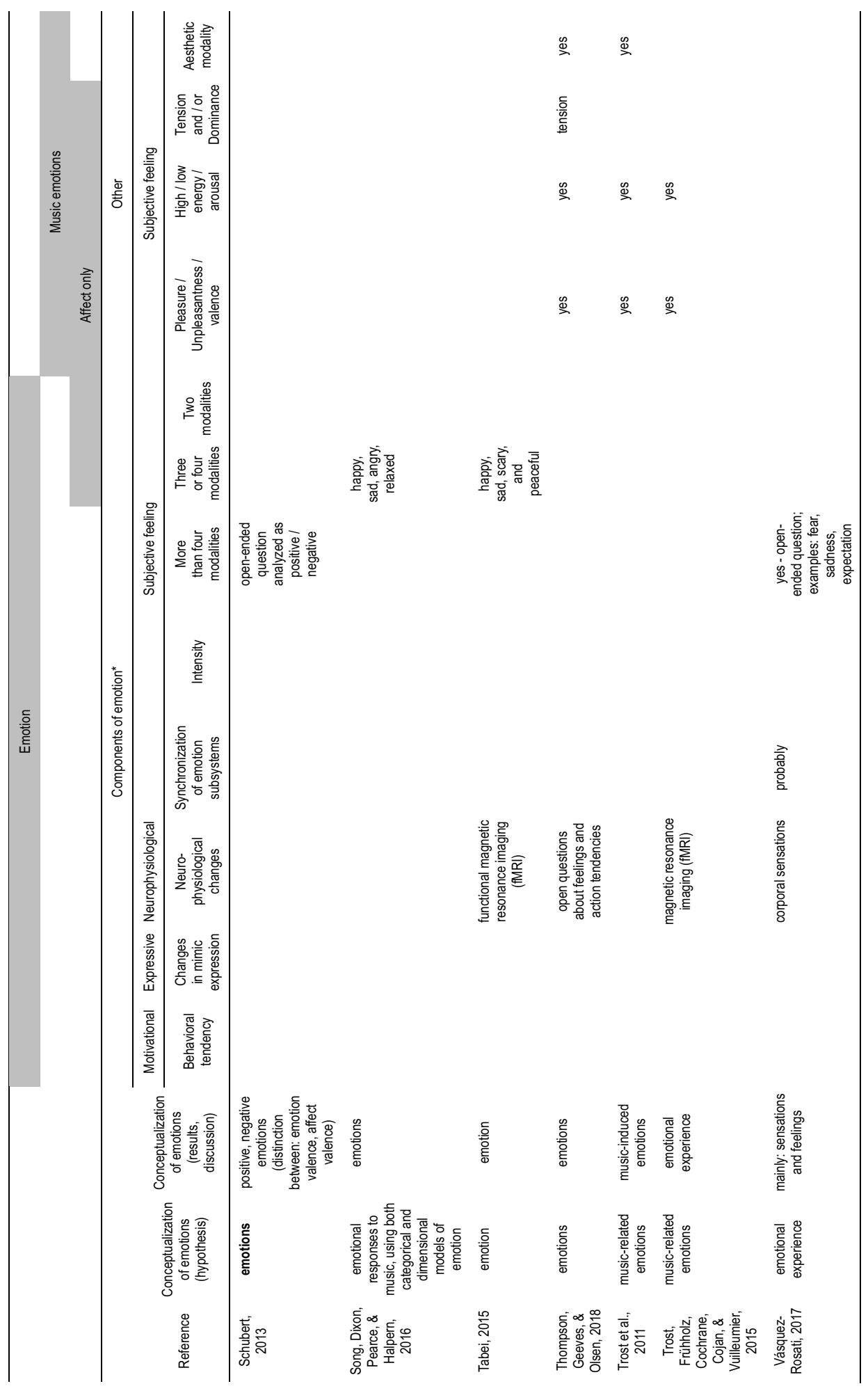




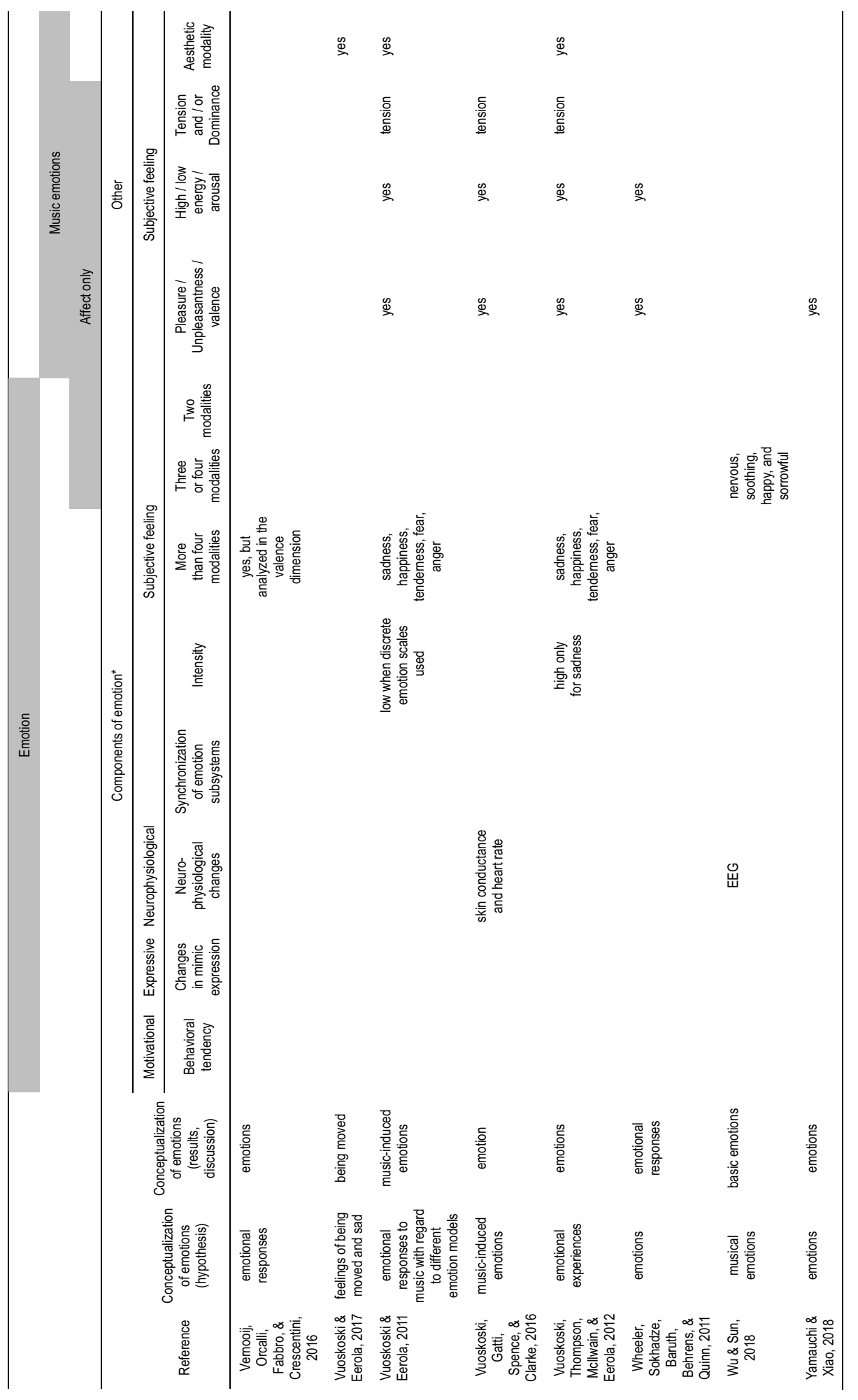




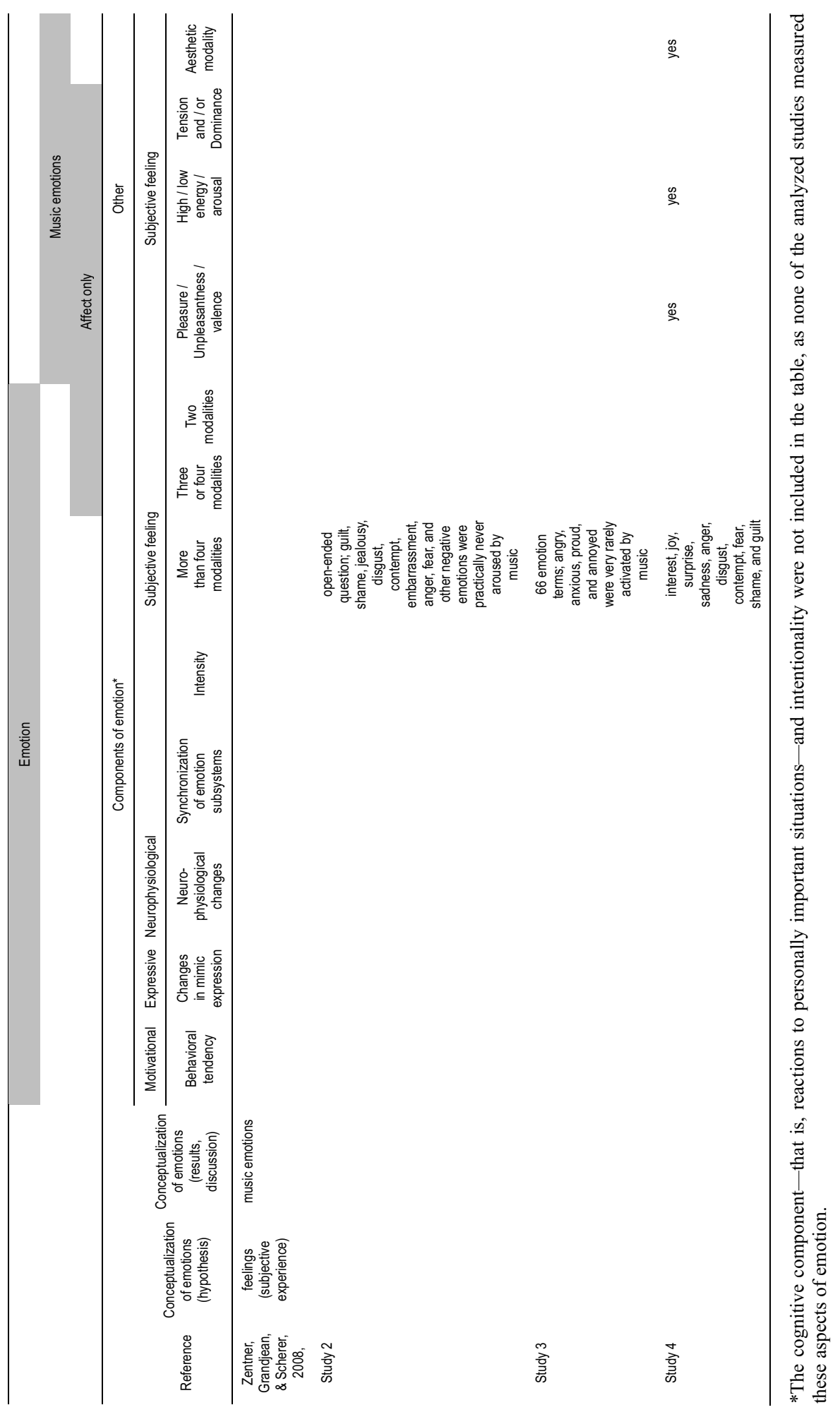

